\title{
Generalized Analytical Approach of the Calculation of the Harmonic Effects of Single Phase Multilevel PWM Inverters
}

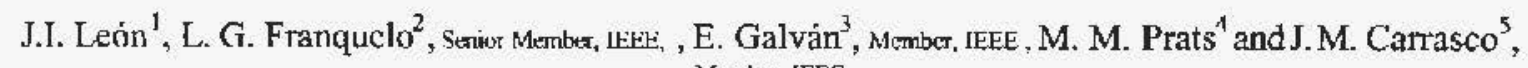 \\ Member, IEEE \\ 1J.1. León, Dept. of electronic engineering. University of Seville, SPAIN e-mail: jileon 0 gte.esi.us.es \\ 2. 3. ${ }^{45}$ Dept. of elcctronic engineering. Universiry of Seville, SPATN
}

Absiraci This paper introduces a generalized analytical approach for calculating the total harmonic distortion THD and its weighted value WTHD for multilevel PWM inverters. The calculation considers one single phast und it tan apply to any number of levels of the inverter In general. Allhough the analysis is based un the assumption of a high number of pulses, the developed equations can also be applied for lower frequency ratius is/fl. The analytical formulas require the characterlstic pargmeters of the PWM only, which are the modulation factor $\mathrm{m}$, the switching frequency fs, the fundamental frequency $\mathrm{fl}$, the effective inductane $\mathrm{I}$. and the DC. link yoltage. Voltnge inverters tith number of levcls $\mathbf{N}$ are considered. It must be noticed that some differe nces appear between the case of $\mathrm{N}$ and and $Y$ even. Severnl parametric curves are calculated to define the specifications of an inverter with $\mathrm{X}$ levels in order to fulfill the harmonic voltage recommendatlons trying to reduec the output signal filtering.

\section{INTRODUCTION}

Multilevel PWM inverters find increasing interest for high power $\mathrm{DC}$ to $\mathrm{AC}$ conversion $[1-4]$. The calculation of THD and WTHD of multilevel inverters is the main subject of some authors. In [5] this calculation was presented but was not generalized. Only the rcsults of several levels of the inverter were presenter. Besides, the presented results were completely individuals and the formulas were $n o t$ generalized for a number $N$ of levels. Using the way of calculation presented in this paper, THD and WTHD can be calculated by generalizing the formulas and studiying all the eases.

Figure 1 shows one possble singlephase topology of a 6- level inverter. The analysis in this paper is based on the assumption of constant DC voltages. One possibility of generating the control signals for a multilevel inverter is the carrier based pulse width modulation.

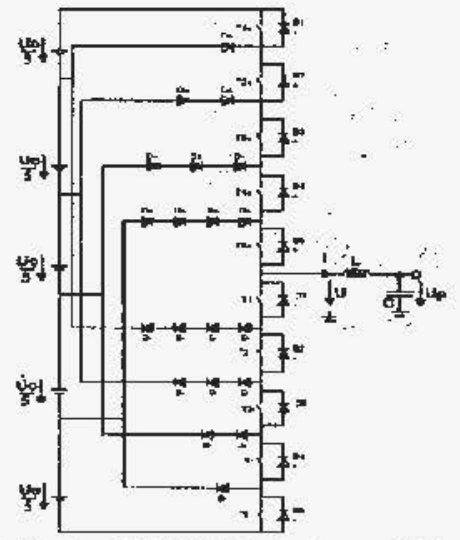

Fig l. Six-level PWM (diode clamped) inverter

\section{THD AND WTHD}

The performance of different PWM techniques and the influence of parancter yariations can be best compared by the total harmonic distortion TIID and the weighted total harmonic distortion WTHD. The TIID is defined by the root of the sum of all squared harmonics of the pulse width modulated voltage $\mathrm{L}(\mathrm{t})$.

$$
T H D=\sqrt{\sum_{i=\frac{2}{L}}^{\infty}\left[\frac{\hat{U}_{i}}{\hat{U}_{i}}\right]^{2}}=\sqrt{\sum_{i=2}^{\infty}\left[\frac{\tilde{U}_{i} \sqrt{2}}{m \dot{U}_{0}}\right]^{2}}
$$

It is normalized to the fundamental amplitude $\hat{V}_{t}=m U$ Uo where $m$ is the modulation factor. The goal of this paper is to calculate some important parameters of a multilevel inverter depending on the number of levels $\mathrm{N}$ of the inverter. These parameters are the duty cycle, the averaged ripple of the current in the single phase leg and the factor (U/Uo). Calculating these parameters, THD and WTHD can be found easily. The weighted total harmonic disturtion WTHD is also based on the sun of all squared harmonics but it considers the order of the harmonics in addition. The higher order (i) of the harmonics, lower their influence to the WTHD tactor.

$$
\text { WTID }=\sqrt{\sum_{=:}^{-}\left[\frac{\vec{U}_{1} \sqrt{2}}{i m C_{0}}\right]^{2}}
$$

It must be noticed that floor $(\mathrm{N} / 2)$ will be denoted as $\mathrm{N}_{\mathrm{ce}}$ in fiure. The floor $(x)$ operator determines the greatest integer less than or equal to the number $x$. In order to carry out these calculations, we must discriminate between the cases of $\mathrm{N}$ even and $\mathrm{N}$ odd. Positive output voltages are only considered due to the fact that the system is completely symmetrical. In [5], this way of calculation is presented but it is generalized in this paper studying all the possible cases. It is defined $u$ as the average output voltage over a period.

The factor $U(u)^{2}$ can be easily calculated using the next formula where $U(t)$ is the output voltage of the single plase in a period.

$$
\tilde{L}(\bar{u})^{2}=\int_{0}^{\tau} u(t)^{2} d t
$$

The RMS value of the fundanental voltage $\hat{L}_{1}(t)$ is simply given by $\hat{U}_{t}=m U_{0}$ while the RMS value of the PWM voltage $U$ can be determined. $U^{2}$ is identical to $U(u)^{2}$ averaged over a period. For symmetrical rcasons it is sufficient to consider one quarter of a period only. It is denoted $a$ as the duty cycle. The hamonic content of 
current $I-(t)$, the current ripple peak to peak $(W)$ and the RMS value of $F(t)(I-(u))$ can be determined as

$$
\begin{aligned}
& I_{-}(t)=\frac{1}{L} \int_{0}^{x}\left(U(t)-\bar{u} U_{0}\right) d t
\end{aligned}
$$

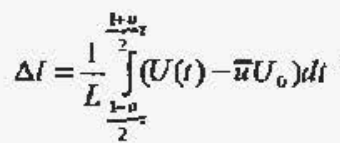

$$
\begin{aligned}
& \tilde{I}_{-}(\overline{i i})=\frac{1}{2 \sqrt{3}} N(\bar{i})
\end{aligned}
$$

The function $u$ can be considered in general $u=m[\sin (a)$ $\left.-k_{3} \sin \left(3 a+f_{3}\right) \div k_{5} \sin \left(5 a+f_{3}\right)\right]$. Therefore, this study can include reference voltages with third and fifth harmonic content. So, several cases are studied.

\section{A. Colculation of the parumeter.}

1. Nodd

The possible outpur voltages of a multilevel inverter

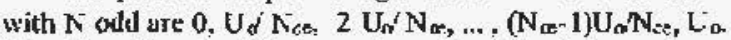
Therefore, $\mathrm{N}_{c c}$ possible intervals can be defined as

$$
\begin{array}{ll}
\text { Interva1 I ? } & \left\{0, \mathrm{U}_{\mathrm{u}} / \mathrm{N}_{\mathrm{ces}}\right\} \\
\text { Interval } 2 ? & \left\{\mathrm{U}_{\mathrm{d}} / \mathrm{N}_{\mathrm{cet}} 2 U_{\mathrm{w}}, \mathrm{v}_{\mathrm{se}}\right\}
\end{array}
$$

$$
\begin{aligned}
& \text { Interval Nce-1? }\left\{\left(\mathrm{N}_{\mathrm{a}}-2\right) \mathrm{U}_{\mathrm{c}} / \mathrm{N}_{\mathrm{ce}},\left(\mathrm{N}_{\mathrm{cr}}-1\right) \mathrm{U}_{\mathrm{o}} \mathrm{N}_{\mathrm{ce}}\right\} \\
& \text { Interval Nice? } \left.\left\{\left(\mathrm{N}_{\mathrm{ce}}\right\}\right) \mathrm{U}_{\mathrm{v}} / \mathrm{N}_{\mathrm{ce}} \cdot \mathrm{U}_{\mathrm{o}}\right\}
\end{aligned}
$$

It must be noticed that it can he denoted as as the duty cycle of interval $k, \Delta \mathrm{I}_{\mathrm{x}}$ as the ripple of the cursent in the interval $k$ averaged over a period and $\left(U / \mathrm{J}_{o}\right)_{k}{ }_{k}^{2}$ with $k=1,2$, $\ldots, \mathrm{N}_{c e}$ These parameters have bcen calculated by increasing iterative operations with $\mathrm{N}$ levels using the formulas commented before.

$$
\begin{aligned}
& a_{k}=\frac{(N-1) \bar{k}}{2}-k+1 \\
& \frac{\Delta J_{2} f_{s} L}{V_{u}}=\frac{2 k(1-k)}{N-1}+\bar{z}(2 k-1)-\frac{(N-1)^{2}}{2} \\
& \left(\frac{\tilde{u}}{U_{c}}\right)_{k}^{2}=\frac{4\left(\frac{\bar{u}(N-1)(2 k-1)}{2}+k(1-k)\right)}{(N-1)^{2}}
\end{aligned}
$$

2. N even

The prossible cutput vollages of a multilevel inverter with $\mathrm{N}$ even are $\left.-\mathrm{U}_{a}(\mathrm{~N}-1), \mathrm{U}_{0}\langle(\mathrm{~N}-1)\}, 2 \mathrm{U}_{\mathrm{s}}(\mathrm{N}-1)\right\}, \ldots,\left(\mathrm{N}_{c e}\right.$ 1) $\mathrm{L}_{\mathrm{D}} ;(\mathrm{N}-1)$, Uo. Therefore, $\mathrm{N}_{\propto}$ intervals can be defined as

Interval 0? $\left\{-\mathrm{U}_{\mathrm{n}}(\mathrm{N}-1), \mathrm{U}_{\mathrm{o}} i(\mathrm{~V}-1)\right\}$ (central interval\} Interval I ? $\left\{\mathrm{U}_{\mathrm{o}} /(\mathrm{N}-1), 2 \mathrm{~L}_{\mathrm{o}}^{-}(\mathrm{N}-1)\right\}$

Interval 2? $\quad\left\{2 \mathrm{U}_{0}(\mathrm{~N}-1), 3 \mathrm{U}_{0} /(\mathrm{N}-1)\right\}$

Interval Nice-2 ? $\left\{\left(\mathrm{N}_{\mathrm{c}}-2\right) \mathrm{U}_{0} /(\mathrm{N}-1),\left(\mathrm{N}_{\mathrm{ce}}-\mathrm{l}\right) \mathrm{U}_{0} /(\mathrm{N}-1)\right\}$ Interval Nice-1? $\quad\left\{\left(\mathrm{N}_{\mathrm{ce}}-1\right) \mathrm{U}_{\mathrm{o}} i(\mathrm{~N}-1), \mathrm{U}_{\mathrm{o}}\right\}$

It must be noticed that a centrol interval appears. This special interval has an output voltage negative (its value is $-U_{\mu^{\prime}}(N-1)$ ) and the other is positive (its valuc is $\left[_{i \mid} /(N-1)\right.$ ).
We can also calculate the parameters $z_{k} \Delta \mathrm{I}_{k}$ and and $\left(\mathrm{U}^{\prime} \mathrm{U}_{\mathrm{b}}\right)_{\mathbf{k}}{ }^{2}$. These paramıeters have been calculated where $\mathbf{k}=$ $0,1,2, \ldots, \mathrm{k}_{\text {cr }}-\mathrm{l}$.

$$
\begin{aligned}
& a_{k}=\frac{(N-1) \bar{z}}{2}-k+\frac{1}{2} \\
& \frac{\Delta I_{k} f_{k} I_{2}}{U_{\mathrm{D}}}=\frac{1-4 k^{2}}{2(\mathrm{~N}-1)}+2 k \bar{a}-\frac{(\mathrm{N}-1) \overline{\mu l}^{2}}{2} \\
& \left(\frac{\tilde{U}}{U_{v}}\right)_{k}^{2}=\left(\frac{1}{2} \cdot \frac{(N-1) \pi}{2}+k\right) t_{n}^{2}+\left(\frac{1}{2}+\frac{(N-1) \bar{\pi}}{2}-k\right) t_{f f}^{2}
\end{aligned}
$$

These expressions are completely valid for the central interval taking into account that in this case $k$ is equal to zerv. Therefore, the expressions for the central interval are the following.

$$
\begin{gathered}
a_{0}=\frac{(N-1) \bar{u}}{2}+\frac{1}{2} \\
\frac{\Delta V_{n} f S L}{U_{0}}=\frac{1}{2(N-1)}-\frac{(n-1) \bar{u}^{2}}{2}(7) \\
\left(\frac{\tilde{U}}{U_{0}}\right)_{0}^{2}=\frac{1}{(N-1)^{2}}
\end{gathered}
$$

\section{B. Colculation of KU fartor}

The KU factur is defined as

$$
K U=\frac{1}{U_{0}^{2}} \sum_{t-2}^{\infty} \tilde{U}_{i}^{s}=\frac{1}{U_{0}^{2}} \sum_{i=1}^{\infty} \tilde{U}_{i}^{2}-\frac{\tilde{U}_{i}^{2}}{U_{0}^{2}}=\frac{U^{2}-\tilde{U}_{1}^{2}}{U_{0}^{2}}
$$

and $\mathrm{U}$ and $\mathrm{U}_{1}$ are detemined as

$$
\tilde{U}_{1}=\frac{m U_{0}}{\sqrt{2}} \quad \tilde{U}^{2}=\frac{2}{\pi} \int_{0}^{\frac{\pi}{2}} \tilde{U}(\bar{u})^{\frac{1}{2}} d \alpha
$$

It must be noticed that firstly it will bc considered $\mathrm{u}=$ $m[\sin (a)]$. Therefore, third and fifth harmonics will be considered in the nextsection of this work.

\section{N odd}

For the first interval, applying the formula described before, it can be used the following expression

$$
U c_{1}=\frac{2}{\pi} \int_{a}^{\frac{5}{3}} \frac{2 \pi}{N-1} d \alpha
$$

If the number of levels of the inverter is greater or equal then 5 , a second interval appeurs and an angle $\beta$ must be calculated. $\beta$ is the angle where the modulation changes the low level to the up level. Therefore, for example if the number of levels is equal to $S, \beta$ is the angle where $\mathrm{m}$ changes between $n=0.5$ and $m>0.5$. In general, Nce angles $\beta_{k}$ must be calculared with $\kappa=5$. These angles follow the rext expression. 


$$
\begin{aligned}
& \beta_{0}=0 \\
& \beta_{A}=\arcsin \left(\frac{2(k-1)}{m(N-1)}\right) \\
& f_{\text {Koe }}=\frac{\pi}{2} \quad \text { with } k-1 . . N_{p e}-1
\end{aligned}
$$

In general, Úç can be determined as

$$
\begin{aligned}
& U c_{j}=\frac{2}{\pi} \sum_{k=1}^{\beta_{\mu_{k}}} \int_{H_{0}}\left(\frac{\tilde{U}}{U_{0}}\right)_{k}^{2} d \alpha \\
& U c_{j}=\frac{2}{\pi} \sum_{i=1}^{j} \int_{p_{k-1}}^{\alpha} \frac{4\left(\frac{\bar{u}(N-I)(2 k-1)}{2}+k(I-\bar{k})\right)}{(N-1)^{2}} d \alpha
\end{aligned}
$$

The parameter $\mathrm{Ug}_{\mathrm{g}}$ is associated with the interval $j N_{c e}>m=(j-1) / N_{c e}$. The function $U$ is defined as the sum of terms $U_{c}$ with $j=1,2, \ldots, N_{\infty c}$. Therefore, $U$ is a function where in can change between 0 and 1 . Finrlly, factor $\mathrm{KU}$ and fuclur THD can be calculated as

$$
K U=U-\frac{m^{2}}{2} \quad T H D=\frac{\sqrt{2 K U}}{m}
$$

The evolution of KU factor and THD factor with the number of levels of the inverter can be calculated. It is shown in figures 8 and 9 .

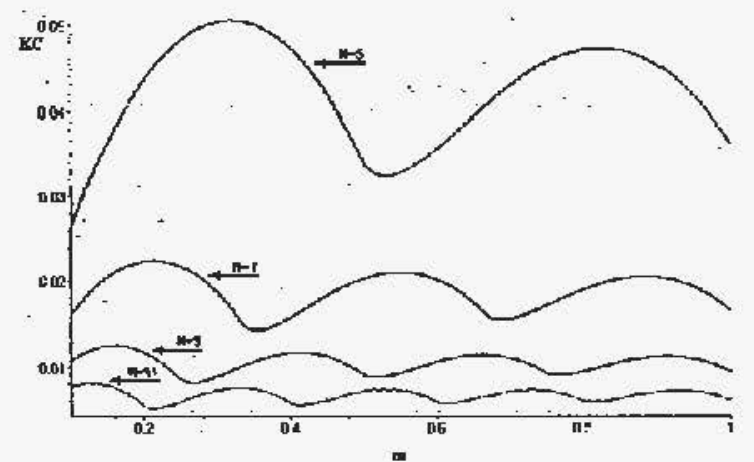

Fig 8. KU fact or evolution for $N$ odd

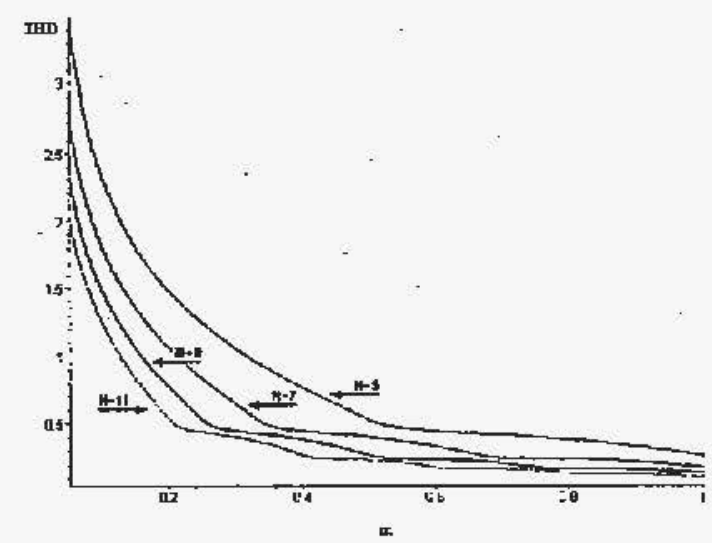

Fig 9. THD factor evolution for $\mathrm{N}$ odd

\section{Neven}

For the central interwal the factor $U_{0}$ can be easily calculated.

$$
U c_{0}=\frac{2}{\pi} \int_{0}^{\frac{\pi}{2}} \frac{1}{(N-1)^{2}} d \alpha
$$

For the first interval (this interval only exists if $N=4$ ) the angic $\boldsymbol{\beta}$ where the mudulation cbanges the low level for the high level must be calculated. So, for example, in the case $\mathrm{N}=4$, this angle marks the change hetween $\mathrm{m}=1 / 3$ and $m>1 / 3$. In general, the number of angles $\beta_{k}$ that must be detemined is $\mathrm{Nce}-\mathrm{I}$ where $\mathrm{N}=4$. The analyticul expressiun of $\beta_{k}$ is

$$
\begin{gathered}
\beta_{0}=0 \\
\beta_{k}=\arcsin \left(\frac{2 k-3}{m(N-1)}\right) \quad(15) \\
\beta_{s e c}=\frac{\pi}{2} \quad \mathrm{k}=1 \ldots \mathrm{N}_{\mathrm{ck}-1}
\end{gathered}
$$

It is defined $u_{i}$ as the initial output volrage of interval $k$, $u_{f}$ as the finsl outpul voltage of interval $k$.. So, in genteral it can be calculated the expression:

$$
U c_{l}=\frac{2}{\pi} \sum_{k=11}^{\beta_{k+1}} \int_{\beta_{1}}^{a_{1}}\left(\frac{\bar{U}}{U_{0}}\right)^{2} d \alpha(16)
$$

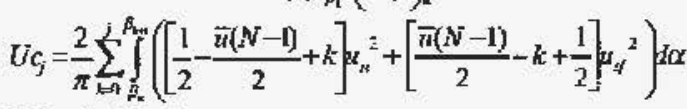

with $j=0 . . . v_{\alpha^{-}}-1$.

It must be taken into account that the factor lion only exists in the interval $1 /(\mathrm{N}-1)=0 \mathrm{~m}=0$. For the other intervals, $\mathrm{Ug}_{\mathrm{j}}$ exists in the interval $(2 \mathrm{j}+1) /(\mathrm{N}-1)>\mathrm{m}=(2 \mathrm{j}-1) /(\mathrm{N}-1)$. So, the function $U$ can be built as the sum of this $\mathrm{Ug}$ factors with $j=0,1, \ldots, N_{c e}-1$. Therefore, $U$ is a function where $m$ changes between 0 and 1 . Finally, factor $\mathrm{KU}$ and factor I'HD can calculated using (13).

So, the evolution of KU factor and THD factor with the number of levels of the inverter can be calculated. It is shown in figures 10 and 11 .

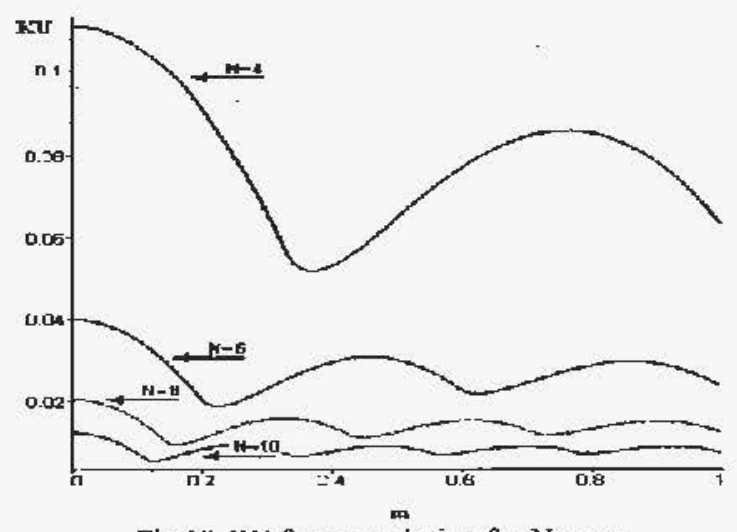

Fig 10. KL factor evolution for N cven 


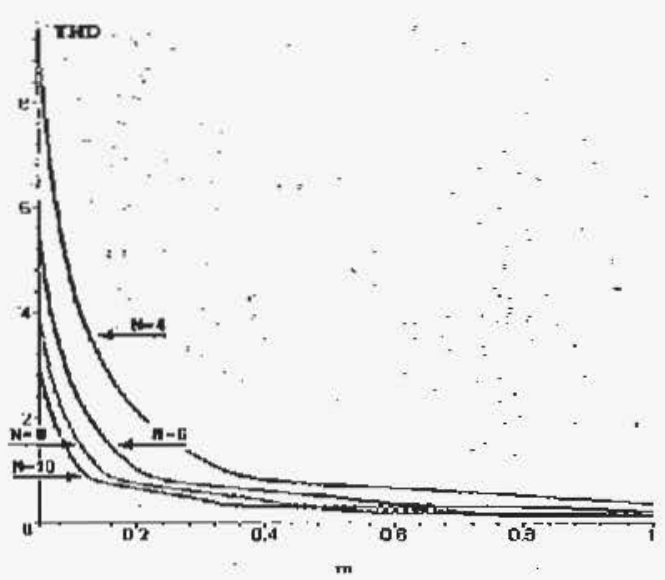

Fig 11. THD factor evulution for N eyen

\section{Calculation of $K I$ fuclor}

\section{N odd}

In gencral, the factors $I_{c_{j}}$ can be caleulated as

$$
I_{j}=\frac{2}{\pi} \sum_{k=1}^{J} \int_{p_{k+1}}^{\beta_{1}}\left(\frac{\Delta_{k} f_{t} L}{U_{0}}\right)^{2} d \alpha
$$

$I c_{j}=\frac{2}{\pi} \sum_{k \rightarrow 1}^{j} \int_{\beta_{2-1}}^{M}\left(\frac{2 h(1-k)}{N-1}+\bar{u}(2 k-1)-\frac{\left(N-1 \bar{u}^{2}\right.}{2}\right)^{2} d x(17)$ with $\mathbf{j}=1 . . . \mathrm{N}_{\mathrm{ww}}$

These factors $\mathrm{K}_{j}$ exist in the interval $f \mathrm{~N}_{\mathrm{ce}}>\mathrm{IIF}(\mathrm{j}-\mathrm{J}) / \mathrm{N}_{\mathrm{ce}}$ So, the function I can be built as the sum of these parameters $\mathrm{k}$, with $j=1, \ldots$, Nce Therefore, $I$ is a function where $m$ changes between 0 and 1 . Finally, factor KI and factor can be calculated WTHD as

$$
K I=\frac{2 \pi f f_{1}^{2}}{3 / s^{2}} \quad W T H D=\frac{\sqrt{2 K J}}{m}
$$

Using these fornulas, the calculation of the paraneters is very fast and easy. So, the evolution of KI factor and WTHID factor with the number of levels of the inverter can be calculated. It is shown in figures 12 and 13 .

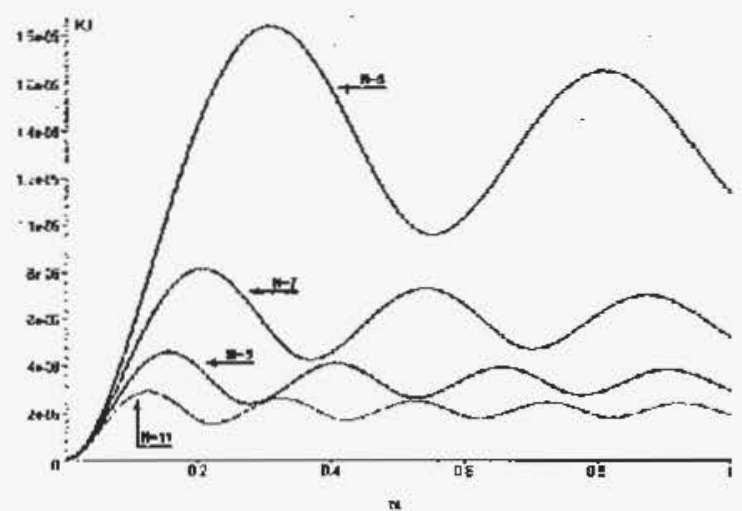

Fig 12. KI factor cvolution for $\mathrm{N}$ odd

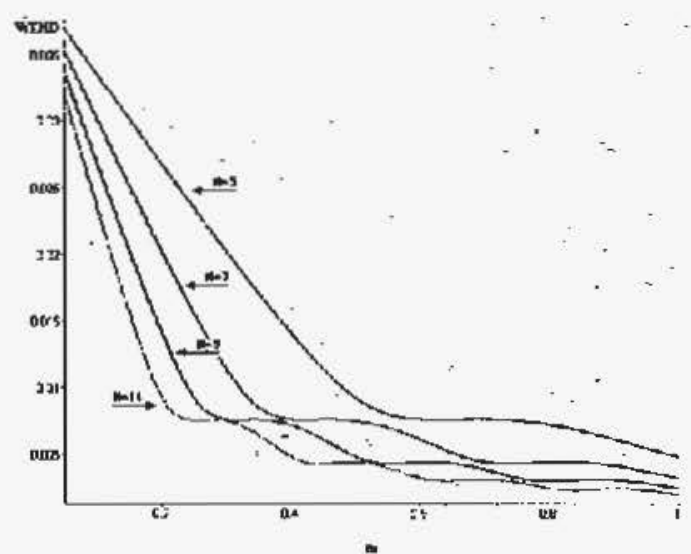

Fig 13. WrHD factor evolution for $\mathrm{N}$ add

\section{N even}

In general, it can bc used

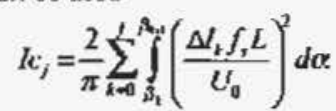

$$
I c_{j}=\frac{2}{\pi} \sum_{k=1}^{1} \int_{\beta_{2}}^{\beta_{21}}\left(\frac{1-4 k^{2}}{2(N-1)}+2 k \bar{u}-\frac{(N-1) \bar{z}^{2}}{2}\right)^{2} d \alpha
$$

with $\mathbf{j}=0, \ldots, \mathrm{N}_{\mathrm{rc}}-1$.

The factor $I c_{0}$ only exists in the interval $I /(\mathrm{N}-1)>\mathrm{M}_{\mathrm{I}}=0$. For the ofher intervals, Ig exists in the interval (2j+1)/(N$1)>m=(2 j-1) /(N-1)$. The function $I$ can be built as the sum of this $\mathrm{Ig}$ factors with $j 0,1, \ldots, \mathrm{N}_{\mathrm{ct}}-1$. Therefore, $\mathbf{I}$ is a function where $m$ changes befween 0 and $\mathrm{J}$. Finally, factor KI and factor WTIID can be calculated with (18).

So, the evolution of KI factor and WTHD factor with the number of levels of the inverter can he calculated. It is shown in figures 14 and 15 .

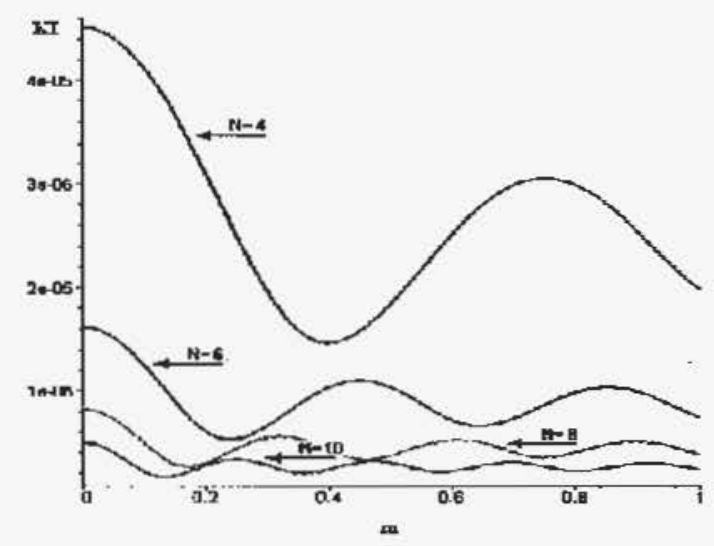

Fig 14. KI factor evolution for $\mathrm{V}$ even 


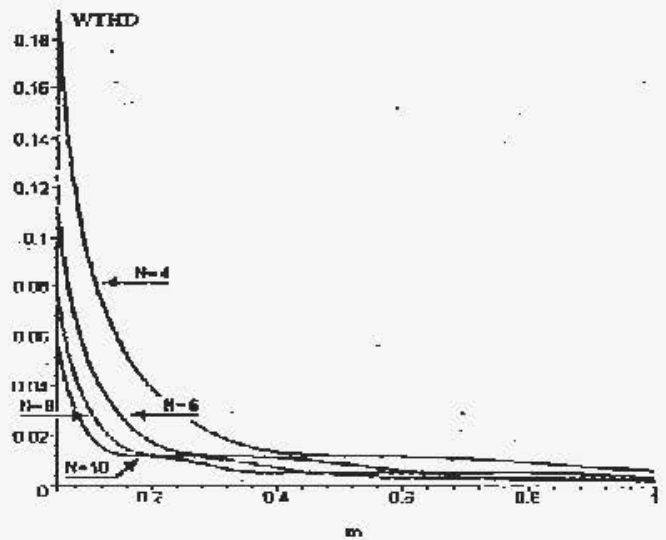

Fig 15. WTHD factor evolution for Nì even

\section{COMPARISION BETWEEN N ODDVEVEN}

In order to compare the THD and WTHD of the inverter with $\mathrm{N}$ oull and $\mathrm{N}$ even, several figures can be shown. THD factor is showin in figures 16 and 17.

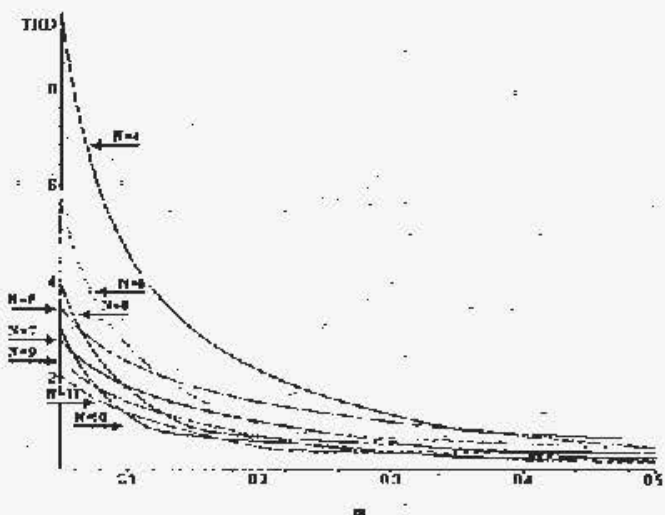

Fig 16. THD faclor evolution with $0.05<\mathrm{m}<0.5$

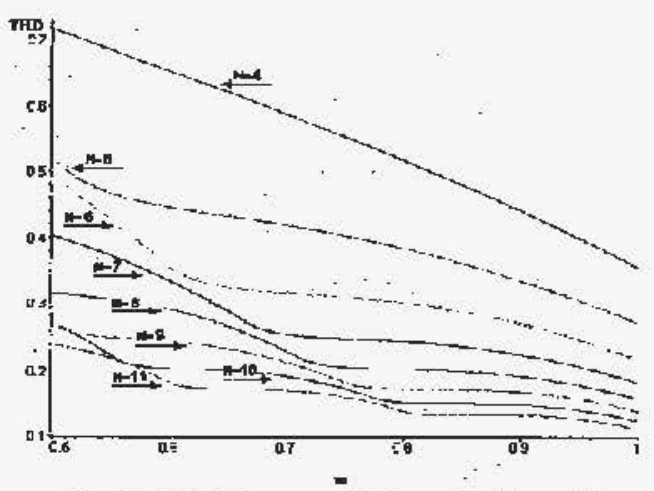

Fig 17. THD factor evolution with $I>m>0.5$

It can be observed clearly that inverters with an even number of levels present l'HD factors greacer than inverters with an odd number of levels when $m$ is small. This phenomenon nocurs due to the fact that inverters with $\mathrm{N}$ odd present zero vectors whereas inverters with $\mathrm{N}$ even do not prescnt that kind of vectors. When $m$ is small, these vectors make easy to follow the reference vector and the enror is low.
When in grows this phenomenon loses importance and the evolution of THD factor is completely logical. Titerefore, for example, THD factor with $\mathrm{N}=6$ is grcatcr than the TIID factor with $\mathrm{N}=7$ and lower than THD factor with $\mathrm{N}=5$.

In the same way, it can be shosin the evolution of WTHD factor with the number of levels. $l t$ is shown in figures 18 and 19 .

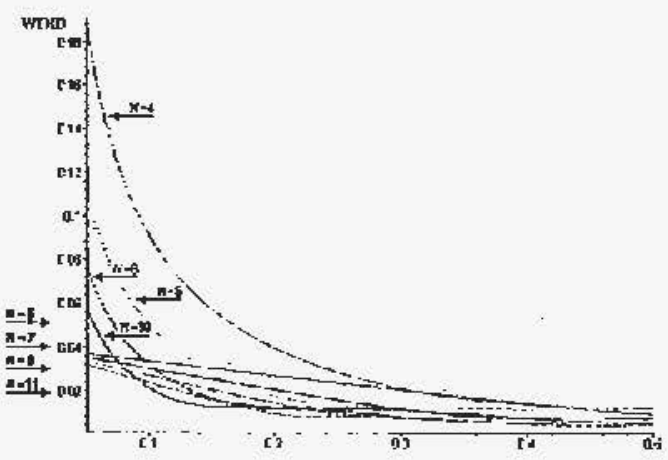

Fig 18. WTHD factor evolution with $0.5>\mathrm{m}>0.05$

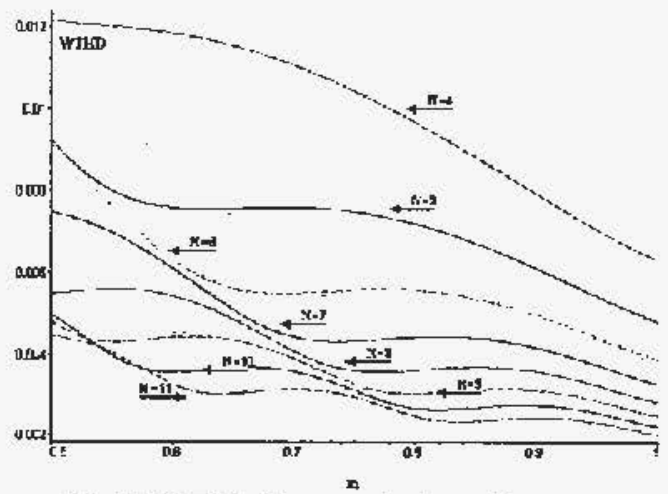

Fig 19. WTHD factor evolution with $1=-m>0.5$

In the same way on that it was commented previously, it can be observed clearly that inverters with an even number of levels present WTHD factors greater than inverters witl. an odd number of levels when $m$ is small. Equally, when in grows this phenontenon loses imporlance and the evolution of WTHD factor is completely logical.

\section{IHIKD AND FIFTH HARMONIC CONTENT}

Now, it will be considered that the function $u$ including hamпnлics. $S a$, in general, $u=m\left[\sin (a)+k_{3} \sin \left(3 a+f_{3}\right)+\right.$ $\left.k_{5} \sin \left(5 a+f_{j}\right)\right]$. Therefore, this sudy includes reference vulinges with third and fifth harmonic content.

The evolution of the factors with harmonic content can be easily calculated using the same fommulas commented before. As an exanple, third harmonic content will be considered. The evolution is represented in the plane $m-k 3$ The results are shown in figures 20-23. Ir must be noticed that these curves include the frgures 16-19 because tht 2-D presented figmres of THD and WTHD are the figures 20-23 with k3equal to zero. So, these 3-D parametric curves are the summary of the calculation. 


\section{CONCI.LSIONS}

In this work, a fast and easy method to calculate the TIID and WTHD tacrors has heen developed. This method is completely generalized and any number of levels can be studicd. This calculation can be carry out in order to know the inverter specifications to fulfill the harmonics recommendation. Besides, the filtering reduction of the output signals can be done thanks to decreasing THU and WIHD harmonics . In this paper, it is shown that inverters will a number cven of levels present THD and WTHD faclors higher than inverters with a number odd of levels when $\mathrm{m}$ is small. It must be noticed that inverters with M>11 achieve harmonic parameters very same and it has not sense the use of inverters with more levels.

There are several practical uses for the method. Firstly, it can be determined the number of levels of a prototype in order to achieve the specifications of distortion knowing the switching frequency $f s$. Secondly, it can be determined the maximum switching frequency $f s$ of a real protolype with $\mathrm{N}$ levels to fulfill the distortion specifications. Thirdly, the maximum modulation index $m$ cun be calculated knowing the specifications of the prototype $(s, \mathrm{~N})$.

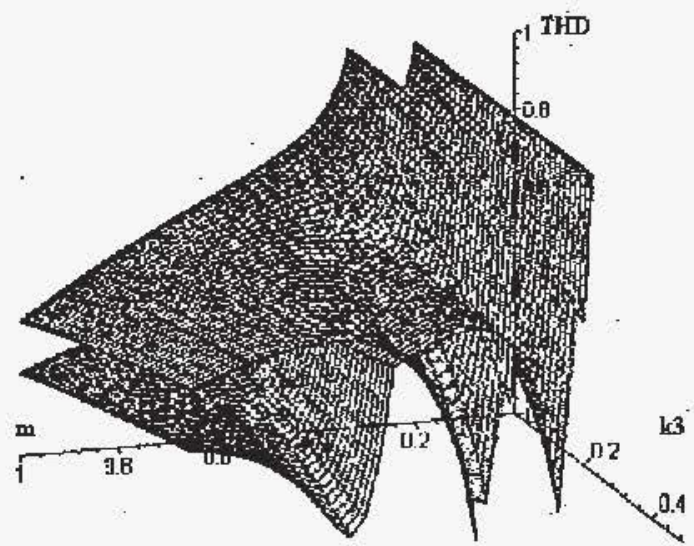

Fig 20. THD factor evolution with third harmonic content with $\mathrm{N}=4$ and $\mathrm{N}=6$

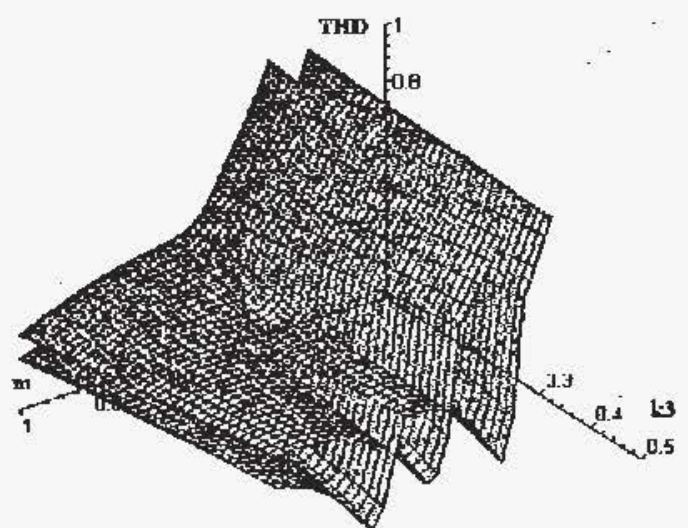

Fig 21. THD factor evolution with third harmonic content with $\mathrm{N}=5$ and $\mathrm{N}=7$

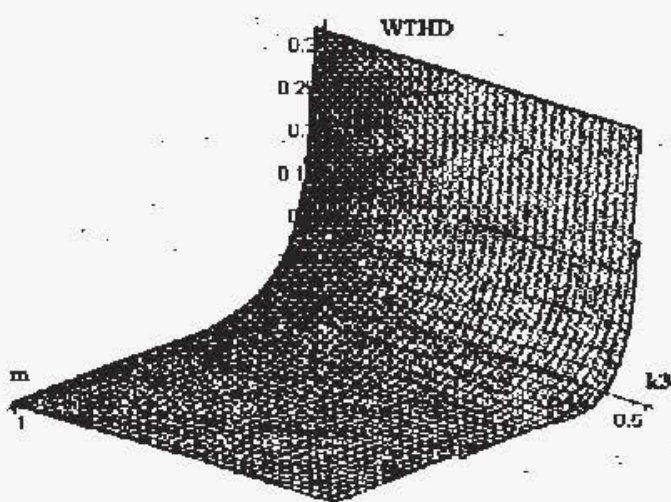

Fig 22. WTHD factor evolution with third harmonic content with $\mathrm{N}=4$ and $\mathrm{N}=6$

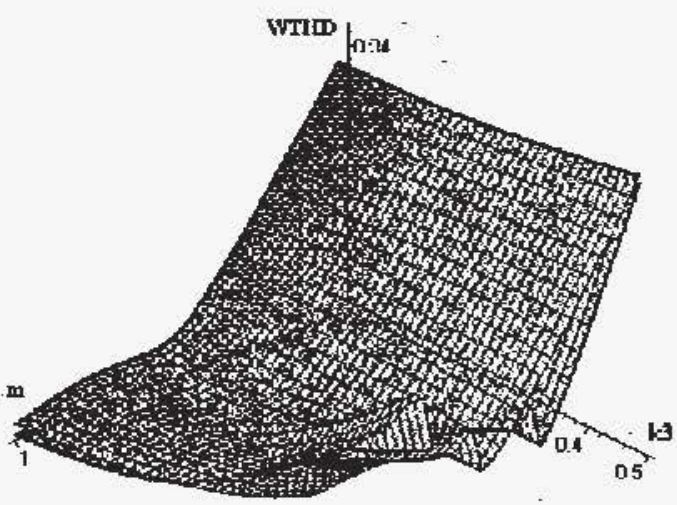

Fig 23. WTHD factor evolution with third barmonic content with $\mathrm{N}=5$ and $\mathrm{N}-7$

So, this mechod is a very useful tool to know a real protolype or to determine a pussible protatype that fulfills the distortion specifications. Besides, the method includes the study of any possible harmonic content. The evolution of THD and WTHD factor can be eusily shown.

\section{REFERFNCES}

[1] K. Teodorescu, F. Blaabjerg, J.D. Pedersm, E. Cengelci, S.U. Sulistijo, B.U. Woo, P. Enjeti, Multilevel Converters - $\Lambda$ Survey" Proc. of EPE'99. Lausanne, FraNce, 1999

[2] J.von Bloh, O.F. Kashani, R.W. De Doncker "Optimisetion of multilevel voltage source converters for Medium-Voltage DC Transnission Systems" International Symp on Ind. Electronics, ISIE2000, Puebla (Mexico) 2000

[3] Dai, S., von Jouanue, A., "A Simple Methul for Balancing the DC-link Voltage of Three-Level Inverters" ConfereNce Proceedings l'ESC 2001

[4] Calais, M., Agelidis, V.G., Borlc, L., "Analysis of Multicarrier PWM Methods for a Single-Phase Five Level Inverter" ConfereNice Proceedings PESC 2001

[5] van der Broeck, H.W., "Analytical calculation of the hamnunic effects of single phase multilevel PWM inverters", 29th Annual ConfereN'ce of the IEEE Indusiria] Electronics Society, IECONO3, pp 243- 248, November 2003, Rounoke, Virginia, USA. 